\title{
Mathematical Algorithms of Patterns for Free-Form Panels
}

\author{
Seunghyun Son ${ }^{1}$, Heni Fitriani ${ }^{2}$, Jeong Tai Kim ${ }^{1}$, Seongseok Go $^{3}$, Sunkuk Kim ${ }^{1}$ \\ ${ }^{1}$ Department of Architectural Engineering, Kyung Hee University \\ 1732 Deogyeong-daero, Giheung-gu, Yongin-si, Gyeonggi-do, Republic of Korea \\ seunghyun@khu.ac.kr; jtkim@khu.ac.kr; kimskuk@khu.ac.kr \\ ${ }^{2}$ Department of Civil Engineering, Universitas Sriwijaya \\ Jl. Srijaya Negara, Bukit Lama, Ilir Bar. I, Kota Palembang, Sumatera Selatan, Indonesia \\ heni.fitriani@unsri.ac.id \\ ${ }^{3}$ School of Architectural Engineering, Chonnam National University \\ 77 Yongbong-ro, Buk-gu, Gwangju, 61186, Republic of Korea \\ ssgo@chonnam.ac.kr
}

\begin{abstract}
Free-Form buildings provide a wide range of diverse and beautiful spaces supported by the development of digital technology. However, there are many difficulties and challenges in realizing free-form curved surfaces at the design and construction phase. Accordingly, panelizing of most free-form buildings is performed only in consideration of reducing the construction cost, or constructability. This panelizing process results in curved surfaces that are against the designer's intention, and this makes it difficult for the designers to come up with the planned beauty. This may happen because the process of designing a free-form building differs from that of a specifically-formed building, and it is difficult to mathematically define the curved surfaces designed. Thus, the purpose of this study is to define mathematical algorithms of patterns for finish panels of free-form buildings based on the basic principles of building design forms such as repetition and gradation. The study results will be used to mathematically review various methods of dividing curved surfaces at the initial design phase of actual free-form building projects, as well as to automatically extract accurate production information and to respond to technical problems that may arise in the construction process.
\end{abstract}

Keywords: Free form building, Mathematical algorithms, Design, Patterns, Panelizing

\section{Introduction}

Free-Form buildings provide a wide range of diverse and beautiful spaces supported by the development of digital technology. However, there are many difficulties and challenges in realizing free-form curved surfaces at the design and construction phase. In particular, there are technical difficulties at the panelizing optimization stage, such as ensuring easier construction and production of members and maintaining the original curved surfaces. Ryu (2012) explained that it is difficult to mathematically define the curved surfaces of free-form buildings and that panelizing is done only in consideration of reducing the construction cost, or constructability [1]. This panelizing process makes it difficult for architectural designers to come up with the planned beauty. Thus, the purpose of this study is to define mathematical algorithms of patterns for finish panels of free-form buildings based on the basic principles of building design forms such as repetition and gradation. Also, the finish panels of the free-form buildings are made of various materials such as concrete, glass, aluminum, and GFRC (Glass Fiber Reinforced Concrete) [2]. In particular, Lee et al. (2015) showed that the free-form concrete panels are superior to lightweight materials in economic efficiency, workability, strength and durability [3]. In this study, we tried to extract production information easily and quickly for the production of free-form concrete panels. The study conformed to the following procedure. 


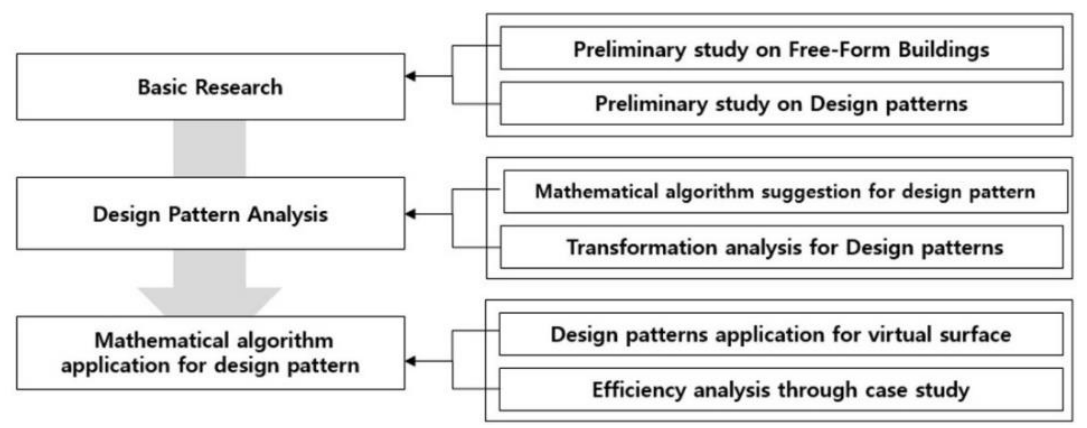

Fig. 1: Research methodology.

First, design patterns are expressed in mathematical algorithms based on the progression using the regularity of parameter equations and functional formulas. Second, various patterns are realized according to the changes in parameters using a mathematical geometric program to change the design. Third, 3D modeling is performed with virtual curved surfaces based on the analyzed design pattern algorithms. In addition, with the 3D modeling cases, the efficiency of Mathematical Algorithms of patterns is verified. The study scope is limited to repetition and gradation, the design patterns that are used the most. Fig1 represents the study method. The study results will allow us to review various methods of dividing curved surfaces at the initial design phase of free-form building projects, improving the project completeness, and at the same time, as the production information obtained from mathematical algorithms, it is expected that it will be critical in appropriately coping with technical problems that may arise upon construction.

\section{Preliminary study}

Currently, there are a wide range of studies on generation of forms and panelizing for free-form buildings. Michael (2010) conducted regarding panelizing optimization for the economic panel production. The author decided that the gap among panels is more economic as close as the maximum tolerance. In addition, panelizing optimization was conducted by using computer simulation [4]. Helmut (2008) conducted the study regarding free-form shape by using single curved panel. In other words, the optimization was conducted to resolve the connection problem between panels when the single curved panel is installed [5]. Helmut (2015) conducted the design analysis about conventional free-form building and introduced the principal of the design then basic materials were suggested to develop modelling system for dividing the panels easily [6]. Yang (2006) suggested the modeling method regarding free-form shape produced by using flat panel [7]. Park (2013) classified free-form shapes into 10 form elements with 34 attributes that correspond to each element and applied them to cases [8]. Ryu (2012) performed quantitative evaluation on panelizing of free-form NURBS surfaces, converted the evaluated panels into BIM data and proposed a model for modelling [1]. Ryu (2013) analysed the domestic/overseas freeform building envelop systems for each case and deducted problems of free-form building construction technologies and their implications [9]. Furthermore, Han (2013) classified the types of high-rise free-form buildings, analysed the characteristics of curved surfaces and suggested basic data for free-form design [10]. Park (2009) analysed the free-form buildings applied with various panelizing methods, and applied Planar Quadrilateral (PQ) Mesh method to virtual models to study its usefulness [11]. As previously mentioned, most preliminary studies are on the techniques of shape and form generation to build actual forms in the construction aspect, and the engineering parts of local free-form architecture is weighted towards 2D design drawings. The studies for application of 3D digital design tools for domestic free-form building designs are under progress. In addition, there are studies on panel division optimization methods by collecting the panel division data of actual free-form buildings, yet it is short of the studies that mathematically analyze pattern division in the design aspect. If it is analyzed mathematically to divide design patterns with regularity, it will be possible to design and construct free-form buildings faster and more accurately. Accordingly, it is needed to mathematically define pattern division for finish panels of free-form buildings. As examining the preliminary study of design patterns, Lim (2016) explained 10 different design patterns for aesthetic designs of free-form buildings such as repetition, gradation, symmetry, contract, unity, balance, harmony, proportion, emphasis and rhythm [12]. However, to mathematically analyze the regularity of design patterns, the overlapping factors need to be excluded. For instance, rhythm cannot be generated unless repetition and gradation are assumed. Also, unity and harmony are the principles that view the whole, not the ones that need to be reviewed in alignment with the partial principles. Gradation-Proportion and emphasis-contrast also have 
mutually overlapping factors. Thus, the study mathematically analyzes repetition and gradation, excluding the overlapping factors.

\section{Mathematical Algorithm Analysis for Design Pattern}

Kwon (2011) defined 'repetition' as repeating the same pattern of shapes and arrangement in a space at regular intervals[13], and Lim (2016) explained 'gradation' as a pattern of shapes and arrangement that gradually changes to get bigger or smaller at a certain ratio[12]. As shown in Fig2 Mathematical Algorithm of Pattern for repetition is proposed using the parameter equations and arithmetic progression. And Fig3 shows Mathematical Algorithm Pattern for gradation.

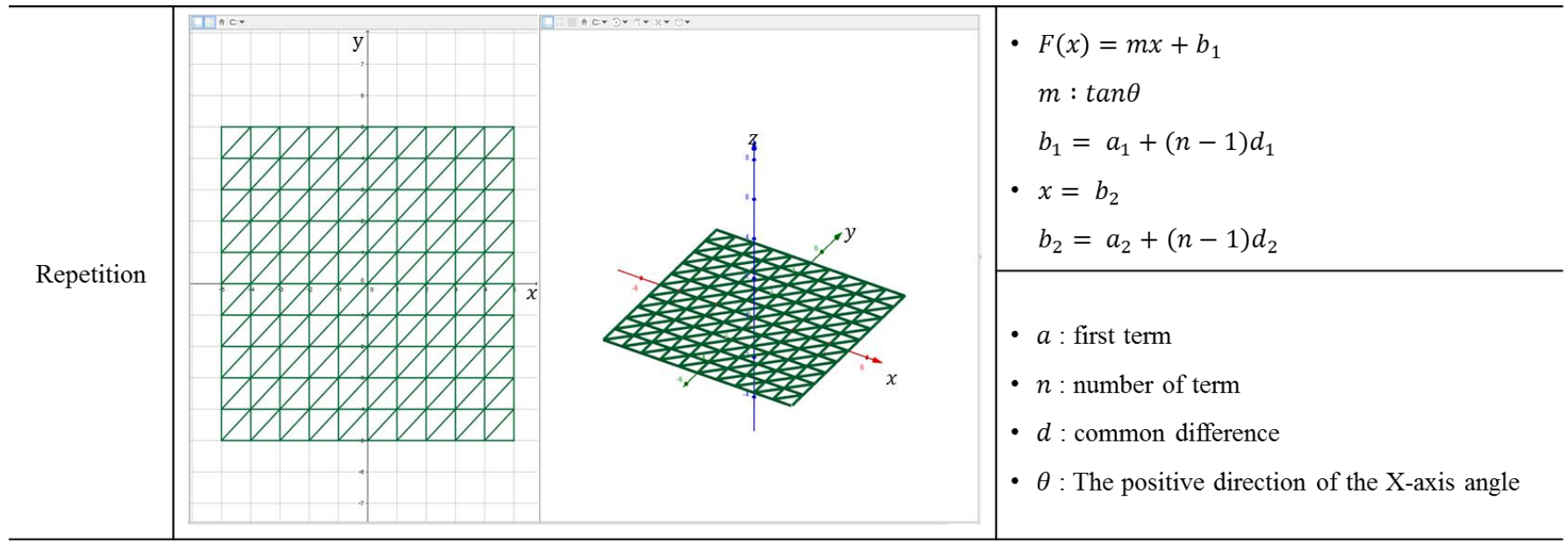

Fig. 2: Mathematical algorithms of repetition pattern.

Table 1 shows the mathematical expression based on the Mathematical Algorithm of Pattern, repetition in Fig2. The range of $\mathrm{x}$ and $\mathrm{y}$ values is expressed in a straight line of repetition pattern within a limited range of $\{(x, y) \mid-5 \leq x \leq 5,-5 \leq y \leq 5, x, y$ is a real number $\}$. An arithmetic progression is used to generate regularity in the $\mathrm{y}$ - intercept of a straight line and for parameterization, and when dividing surfaces, the shapes and arrangement are to at regular intervals. In addition, $\mathrm{x}$-axis and positive direction angle $(\boldsymbol{\theta})$ that determine the gradient of a division line are parameterized so that the pattern form can be changed.

Table 1: Mathematical expressions of Repetition pattern.

\begin{tabular}{|c|r|r|r|}
\hline $\mathrm{n}$ & $a_{1}=-9, d_{1}=1, \theta=\pi / 4$ & $a_{1}=-5, d_{1}=1, \theta=0$ & $a_{2}=-5, d_{2}=1$ \\
\hline 1 & $\mathrm{f}_{1}(\mathrm{x})=\mathrm{x}-9$ & $\mathrm{f}_{2}(\mathrm{x})=-5$ & $\mathrm{x}=-5$ \\
\hline 2 & $\mathrm{f}_{1}(\mathrm{x})=\mathrm{x}-8$ & $\mathrm{f}_{2}(\mathrm{x})=-4$ & $\mathrm{x}=-4$ \\
\hline 3 & $\mathrm{f}_{1}(\mathrm{x})=\mathrm{x}-7$ & $\mathrm{f}_{2}(\mathrm{x})=-3$ & $\mathrm{x}=-3$ \\
\hline 4 & $\mathrm{f}_{1}(\mathrm{x})=\mathrm{x}-6$ & $\mathrm{f}_{2}(\mathrm{x})=-2$ & $\mathrm{x}=-2$ \\
\hline 5 & $\mathrm{f}_{1}(\mathrm{x})=\mathrm{x}-5$ & $\mathrm{f}_{2}(\mathrm{x})=-1$ & $\mathrm{x}=0$ \\
\hline 6 & $\mathrm{f}_{1}(\mathrm{x})=\mathrm{x}-4$ & $\mathrm{f}_{2}(\mathrm{x})=0$ & $\mathrm{x}=1$ \\
\hline 7 & $\mathrm{f}_{1}(\mathrm{x})=\mathrm{x}-3$ & $\mathrm{f}_{2}(\mathrm{x})=1$ & $\mathrm{x}=2$ \\
\hline 8 & $\mathrm{f}_{1}(\mathrm{x})=\mathrm{x}-2$ & $\mathrm{f}_{2}(\mathrm{x})=2$ & $\mathrm{x}=3$ \\
\hline 9 & $\mathrm{f}_{1}(\mathrm{x})=\mathrm{x}-1$ & $\mathrm{f}_{2}(\mathrm{x})=3$ & $\mathrm{x}=4$ \\
\hline 10 & $\mathrm{f}_{1}(\mathrm{x})=\mathrm{x}$ & $\mathrm{f}_{2}(\mathrm{x})=4$ & - \\
\hline 11 & $\mathrm{f}_{1}(\mathrm{x})=\mathrm{x}+1$ & $\mathrm{f}_{2}(\mathrm{x})=5$ & - \\
\hline 12 & $\mathrm{f}_{1}(\mathrm{x})=\mathrm{x}+2$ & - & - \\
\hline 13 & $\mathrm{f}_{1}(\mathrm{x})=\mathrm{x}+3$ & - & - \\
\hline 14 & $\mathrm{f}_{1}(\mathrm{x})=\mathrm{x}+4$ & - & - \\
\hline 15 & $\mathrm{f}_{1}(\mathrm{x})=\mathrm{x}+5$ & - & - \\
\hline 16 & $\mathrm{f}_{1}(\mathrm{x})=\mathrm{x}+6$ & - & - \\
\hline 17 & $\mathrm{f}_{1}(\mathrm{x})=\mathrm{x}+7$ & - & - \\
\hline 18 & $\mathrm{f}_{1}(\mathrm{x})=\mathrm{x}+8$ & - & $\mathrm{x}$ \\
\hline 19 & $\mathrm{f}_{1}(\mathrm{x})=\mathrm{x}+9$ & & - \\
\hline
\end{tabular}




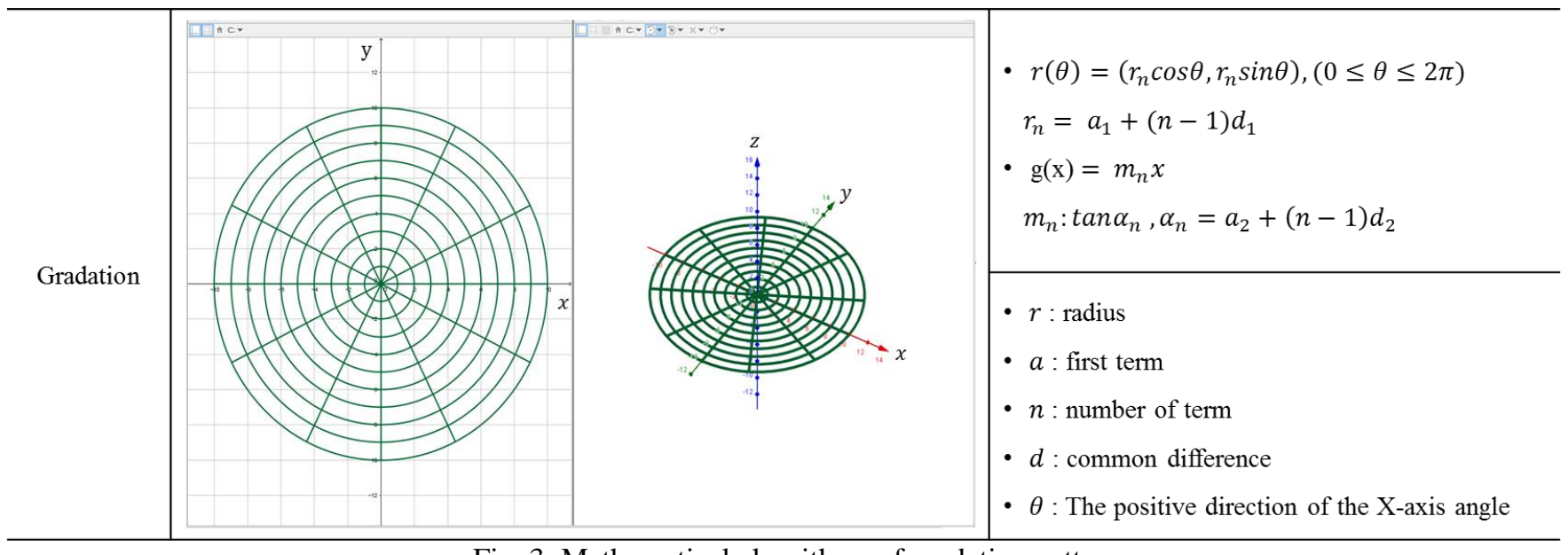

Fig. 3: Mathematical algorithms of gradation pattern.

Table 2 is the mathematical expression based on the Mathematical Algorithm of Pattern gradation in Fig3. The range of $\mathrm{x}$ and $\mathrm{y}$ values is limited to $\left\{(x, y) \mid x^{2}+y^{2} \leq 10, x, y\right.$ is a real number $\}$, and when dividing surfaces, to gradually increase or decrease the shape and arrangement at a certain ratio, the radius of a circle (r) and rotation angle $(\boldsymbol{\theta})$ are parameterized. So, various curved surfaces can be generated based on the control of division line intervals and rotation angle.

Table 2: Mathematical expressions of Gradation pattern.

\begin{tabular}{|c|c|c|}
\hline $\mathrm{n}$ & $a_{1}=1, d_{1}=1$ & $a_{2}=0, d_{2}=\pi / 6$ \\
\hline 1 & $\mathrm{r}(\theta)=(\cos \theta, \sin \theta)$ & $\mathrm{y}=0$ \\
\hline 2 & $\mathrm{r}(\theta)=(2 \cos \theta, 2 \sin \theta)$ & $\mathrm{g}(\mathrm{x})=(1 / \sqrt{3}) \mathrm{x}$ \\
\hline 3 & $\mathrm{r}(\theta)=(3 \cos \theta, 3 \sin \theta)$ & $\mathrm{g}(\mathrm{x})=\sqrt{3} \mathrm{x}$ \\
\hline 4 & $\mathrm{r}(\theta)=(4 \cos \theta, 4 \sin \theta)$ & $\mathrm{g}(\mathrm{x})=(-\sqrt{3}) \mathrm{x}$ \\
\hline 5 & $\mathrm{r}(\theta)=(5 \cos \theta, 5 \sin \theta)$ & $\mathrm{g}(\mathrm{x})=-(1 / \sqrt{3}) \mathrm{x}$ \\
\hline 6 & $\mathrm{r}(\theta)=(6 \cos \theta, 6 \sin \theta)$ & - \\
\hline 7 & $\mathrm{r}(\theta)=(7 \cos \theta, 7 \sin \theta)$ & - \\
\hline 8 & $\mathrm{r}(\theta)=(8 \cos \theta, 8 \sin \theta)$ & - \\
\hline 9 & $\mathrm{r}(\theta)=(9 \cos \theta, 9 \sin \theta)$ & \\
\hline
\end{tabular}

Thus, when dividing patterns in a plane using the Mathematical Algorithms of Patterns, it is easier and faster to check the formula of division lines, making it easier to extract the intersection point of division lines. Fig4 is a 3D model created through one-to-one correspondence of Z-value equation that generates virtual curved surfaces in the intersection point of division lines extracted. 


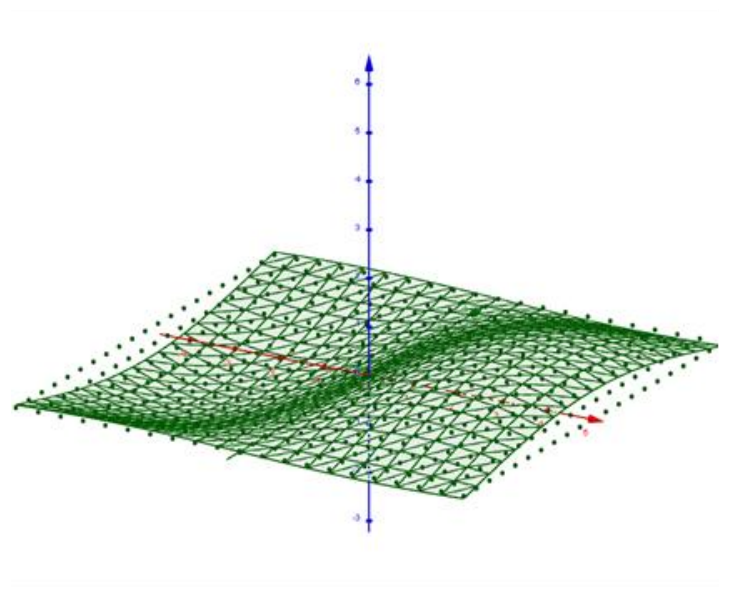

(a) Repetition

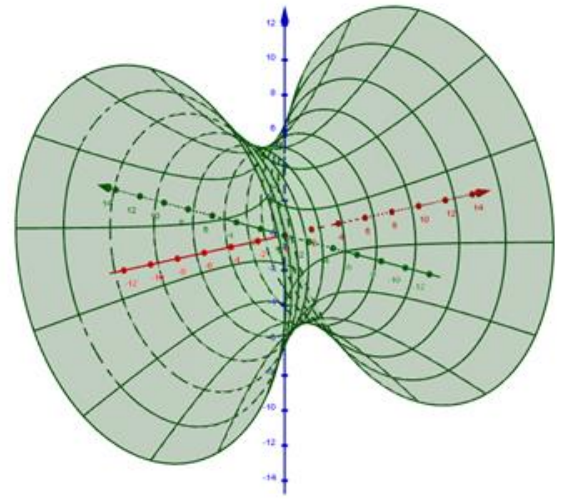

(b) Gradation

Fig. 4: 3D modeling example of a pattern application.

The procedure for 3D modeling of repetition patterns is as follows. After setting as $\mathrm{x}_{\max }=5, \mathrm{x}_{\min }=-5$, intervals are divided into parameter, $\mathrm{N}=20$ and they are to be maintained at regular intervals of $\mathrm{dx}=0.5$. With the same method, after setting as $\mathrm{y}_{\max }=5, \mathrm{y}_{\min }=-5$, they are divided into $\mathrm{N}=20$ to extract $(\mathrm{x}, \mathrm{y})$ coordinates in a plane as shown in fig5(a). The intervals of coordinates are to be controlled by the parameter, $\mathrm{N}$. To generate 3D curved surfaces, trigonometric function is applied to the height, $Z$-value and $z=\sin (x / 2) \cos (y / 3)$ is input. To verify generation of various curved surfaces based on the $Z$-value input formula, the study defined the formula into 3 types of matrix $1=\left\{0.3 x y, 0.2\left(x^{2}-y^{2}\right)\right.$, $\sin (\mathrm{x} / 2) \cos (\mathrm{y} / 3)\}$ and expressed it as the matrix. Fig5(b) demonstrates the virtual surfaces generated based on $(\mathrm{x}, \mathrm{y}, \mathrm{z})$.

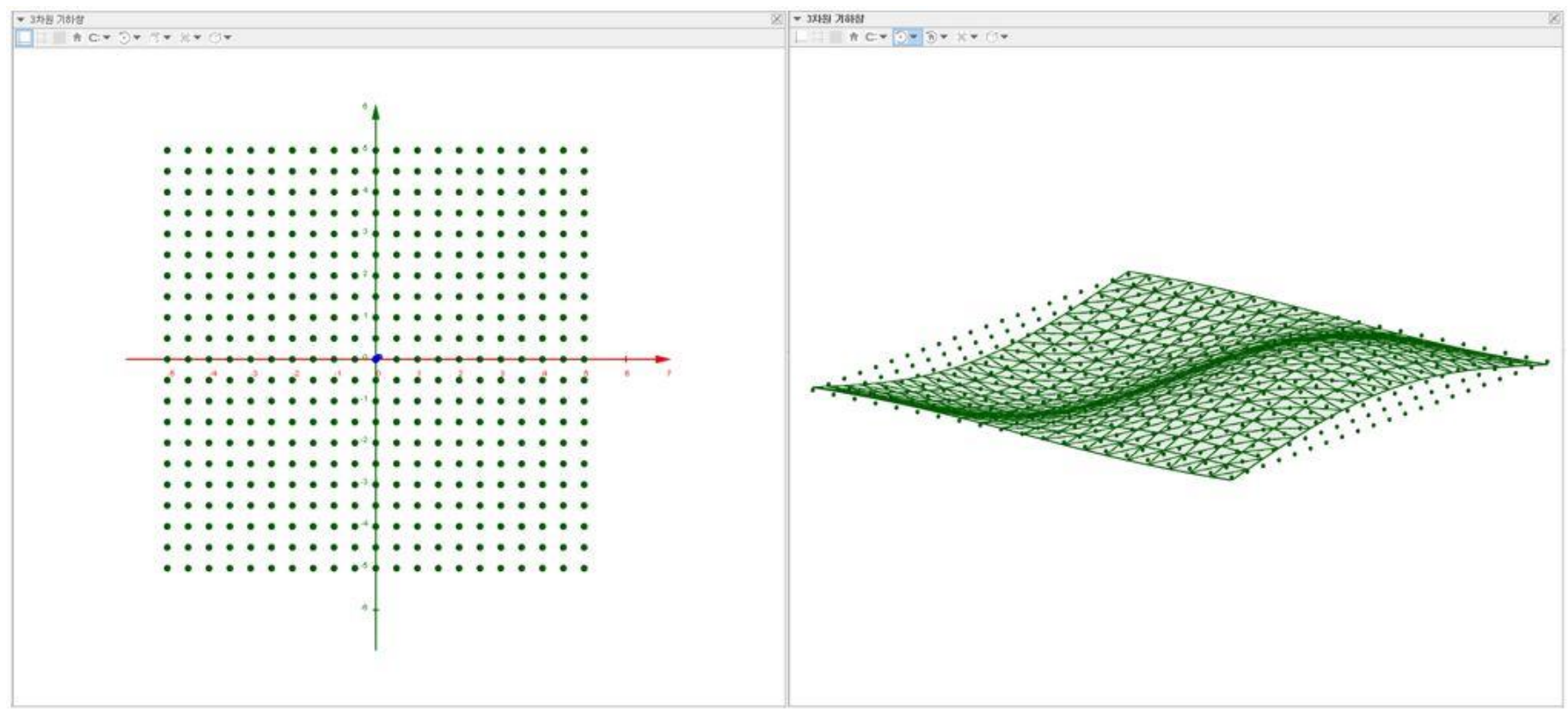

Fig. 5: Extraction of coordinates (a), Creation of virtual surface (b).

The procedure for 3D modeling of gradation patterns is as follows. After defining a curve that determines the shape of $3 \mathrm{D}$ virtual surfaces, the curved surfaces are rotated to generate a 3D model of gradation patterns. First, the explicit function of a hyperbola, $f(x)=\operatorname{sqrt}\left(0.5^{2}\left(1+x^{2} /(-1)^{2}\right)\right.$, to express the curve of xy plane is defined as shown in Fig6(a). 
Second, $f(x)$ is set with the rotation angle of $\theta=\pi / 6$ based on the xy plane, and then rotated at a certain ratio to extract 6 curves as shown in Fig6(b). The angle $\theta$ between the extracted curves is parameterized to control the number of division lines and the shape of rotation. Third, a parameter equation of circles is used to generate a gradation pattern of virtual curved surfaces, and the curve $[(\mathrm{x}, \mathrm{f}(\mathrm{x}) \cos (\mathrm{u}), \mathrm{f}(\mathrm{x}) \sin (\mathrm{u})), 0 \leq \mathrm{u} \leq \pi,-10 \leq \mathrm{x} \leq 10, \mathrm{~d}=2]$ is defined. As a result, 11 semi-circular curves in the yz plane that pass through 6 curves extracted in Fig7(b) are extracted as shown in Fig6(c), generating the division line of gradation pattern. The interval $\mathrm{d}$ between the semi-circular curves is parameterized to control the number of semi-circular curves. Lastly, the curved surfaces that pass through the extracted division line $[(\mathrm{x}, \mathrm{f}(\mathrm{x})$ $\cos (\mathrm{u}), \mathrm{f}(\mathrm{x}) \sin (\mathrm{u})),-10 \leq \mathrm{x} \leq 10,0 \leq \mathrm{u} \leq \pi]$ are defined to generate virtual curved surfaces as demonstrated in Fig6(d). The range of $\mathrm{x}$-value is parameterized as well to express various types of rotation.

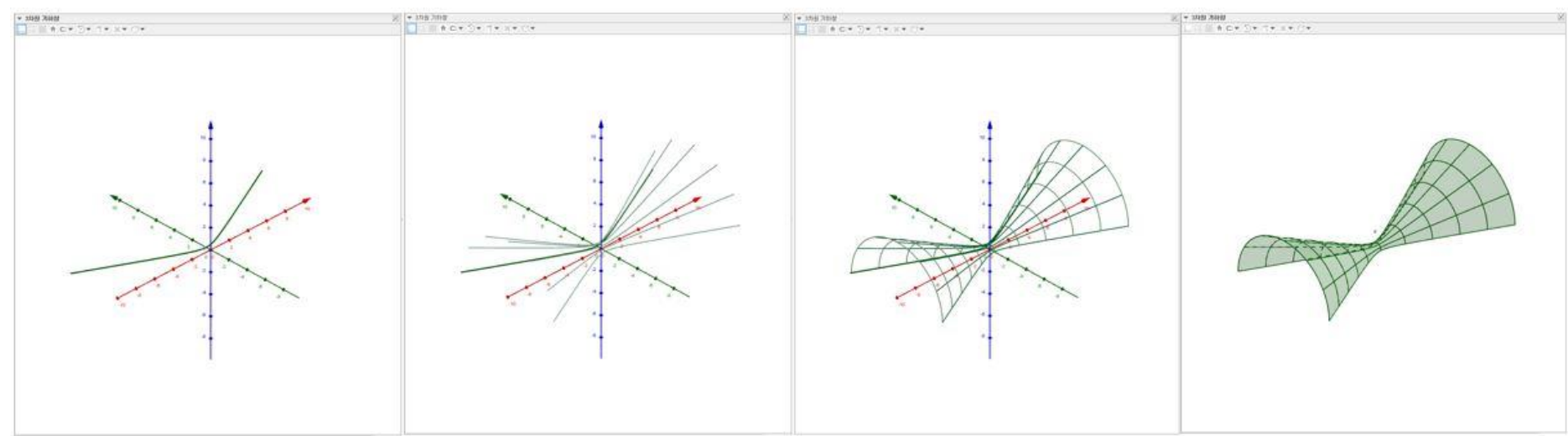

Fig. 6: definition of curve $\mathrm{f}(\mathrm{x})$ for xy plane (a), extraction of $\pi$ / 6 intervals curve for $\mathrm{f}(\mathrm{x})(\mathrm{b})$, Addition of semi-circular curve (c), Creation of virtual surface $(d)$.

As described above on the 3D model of Mathematical Algorithms of Patterns, when the design pattern defined in a plane is applied to the panelizing process of free-form buildings, various methods of curved surface division can be mathematically reviewed at the initial design phase, and owing to automatic extraction of accurate information on generation of surfaces, it is expected to realize easier and faster construction. In addition, it is anticipated that free-form surfaces can be divided variously based on the changes to the parameters set in the process of constructing 3D models. Fig7 and Fig8 shows the cases of changed 3D models owing to the parameter changes.

\begin{tabular}{l|l|l|l}
\hline $\mathrm{Z}=\sin (\mathrm{x} / 2) \cos (\mathrm{y} / 3)$ & $\mathrm{Z}=0.2\left(\mathrm{x}^{2}-\mathrm{y}^{2}\right)$ & $\mathrm{Z}=-0.07\left(\mathrm{x}^{2}+\mathrm{y}^{2}\right)$ \\
\hline $\mathrm{N}=15$ & & & \\
\hline $\mathrm{N}=10$ & & & \\
\hline & & & \\
\hline
\end{tabular}

Fig. 7: Transformation case of repetition patterns. 
In case of the repetition pattern in Fig7, to generate various curved surfaces, the function that determines z-value is transformed into $\mathrm{z}=\sin (\mathrm{x} / 2) \cos (\mathrm{y} / 3), \mathrm{z}=0.2\left(\mathrm{x}^{2}-\mathrm{y}^{2}\right), \mathrm{z}=-0.07\left(\mathrm{x}^{2}+\mathrm{y}^{2}\right)$ to check for any transformation. Also, $\mathrm{N}$ that determines the intervals of $\mathrm{x}$, $\mathrm{y}$ values is transformed into $\mathrm{N}=15, \mathrm{~N}=10, \mathrm{~N}=5$, which makes it possible to control the number of panels, to check the completeness of surfaces based on the number of panels.

\begin{tabular}{l|l|l|l}
\hline & $\mathrm{F}(\mathrm{x})=\operatorname{sqrt}\left(5^{2}\left(1+\mathrm{x}^{2} /(-5)^{2}\right)\right.$ & $\mathrm{F}(\mathrm{x})=\operatorname{sqrt}\left(10^{2}\left(1-\mathrm{x}^{2} /(12)^{2}\right)\right.$ & $\mathrm{F}(\mathrm{x})=-\frac{1}{3}\left(x^{3}-3 x^{2}-2\right)$ \\
\hline \multirow{1}{*}{$\theta=180$} & & & \\
\hline
\end{tabular}

Fig. 8: Transformation case of gradation patterns.

In case of the gradation pattern in Fig8, a function that determines the shape of rotation is transformed into $\mathrm{f}(\mathrm{x})=$ $\operatorname{sqrt}\left(5^{2}\left(1+x^{2} /(-5)^{2}\right), f(x)=\operatorname{sqrt}\left(10^{2}\left(1-x^{2} /(12)^{2}\right), f(x)=-1 / 3\left(x^{3}-3 x^{2}-2\right)\right.\right.$ to check various types of rotation generated. Moreover, the rotation angle $\theta$ is transformed into $\pi$ and $2 \pi$ to check any transformation based on the rotation angle, and the form is partially generated according to the range of $\mathrm{x}$. If such is applied to designing each part of free-form buildings, it is expected to create a wide range of designs.

\section{Conclusion}

Currently, a wide range of complicated free-form buildings are increasingly built owing to the development of digital tools, yet there are many difficulties in realizing free-form surfaces that are geometrically complicated in the design and construction phase. Accordingly, it results in curved surfaces that are against the designer's intention, and this makes it difficult for the designers to come up with the planned beauty. Thus, the study defined mathematical algorithms of patterns for finish panels of free-form buildings based on the basic principles of building design forms such as repetition and gradation. The plane coordinates ( $\mathrm{x}, \mathrm{y}$ coordinates) extracted through the defined mathematical algorithm are substituted into the z-value function equation that generates the free-form surface. Thus, the extracted function value forms an free-form surface, and has aesthetic beauty by the pattern of repetition and gradation pattern. To do so, repetition and gradation, excluding the overlapping factors among the principles of design form, were mathematically analyzed and Mathematical Algorithms of Patterns were proposed. In addition, 3D modeling with virtual surfaces is adopted for the case study of transformation, verifying its efficiency. As a result, firstly, it was found that it is easy to mathematically divide design patterns of repetition and gradation for free-form buildings using the Mathematical Algorithms of Patterns, and that such can be accurately expressed. Secondly, it was revealed that free-form surfaces can be transformed owing to the changes to the parameters of the Mathematical Algorithms of Patterns. Thirdly, it was found that it is easy to extract information on generation of free-form surfaces realized based on the Mathematical Algorithms of Patterns. With these, it is believed that various design patterns can be mathematically reviewed in the initial design phase of free-form building projects, and that the completeness of projects may be improved as various methods of curved surface division arising from parameter changes can be examined. In addition, the study results will be used as production 
information based on mathematical algorithms, which will be critical in appropriately dealing with technical problems in relation to construction that may be generated.

\section{References}

[1] J.-W. Ryu, "BIM-based Panelizing Optimization for Architectural Freeform Surfaces," Ph.D. dissertation, Dept. Architectural Engineering, Seoul National University.

[2] K. Kim, K. Son, E. D. Kim, S. Kim, "Current trends and future directions of free-form building technology," Architectural Science Review, vol. 58, no. 3, pp. 230-243, 2015.

[3] D. Lee, W. K. Hong, J. T. Kim, S. Kim, "Conceptual Study of Production Technology of Free-Form Concrete Segments," International Journal of Engineering and Technology, vol. 7, no. 4, p. 321, 2015.

[4] M. Eigensatz, M. Kilian, A. Schiftner, N. J. Mitra, H. Pottmann, M. Pauly, "Paneling architectural freeform surfaces," ACM transactions on graphics (TOG), vol. 29, no. 4, p. 45, 2010.

[5] H. Pottmann, A. Schiftner, P. Bo, H. Schmiedhofer, W. Wang, N. Baldassini, J. Wallner, "Freeform surfaces from single curved panels," ACM Transactions on Graphics (TOG), vol. 27, no. 3, p. 76, 2008.

[6] H. Pottmann, M. Eigensatz, A. Vaxman, J. Wallner, “Architectural geometry," Computers \& graphics, vol. 47, pp. 145-164, 2015.

[7] Y. Liu, H. Pottmann, J. Wallner, Y. L. Yang, W. Wang, "Geometric modeling with conical meshes and developable surfaces," ACM Transactions on Graphics (TOG), vol. 25, no. 3, pp. 681-689, 2006.

[8] S. J. Park, K. S. Hong, "A study on the process to create forms of digital design tools shown in freeform architecture and their attributes," Korea Journal of Basic Design \& Art, vol. 15, no. 1, pp. 189-197, 2014.

[9] H. K. Ryu, "Deduction of Considerations During Design and Construction by Analysing Domestic and Abroad Case Analysis of Freeform Building Envelope," Korea Journal of Construction Engineering and Management, vol. 14, no. 4, pp. 84-96, 2013.

[10] J. Y. Han, "A Study on Classification and Feature of Double-curved Surface Fabrication Techniques in Freeform Architecture," Journal of the Architectural Institute of Korea, vol. 29, no. 12, pp. 3-14, 2013.

[11] H. S. Park, "A study on a Surface Generation Method of Free-Form Architecture using a Planar Quadrilateral Mesh Technique," M.A. thesis, Dept. Architectural Engineering, Hanyang University.

[12] J. Y. Lim, et al, "Discrete-cosine/sine-transform based motion estimation," in Proceedings of the ICEAI International Congress on Engineering and Information, Osaka, Japan, pp. 1149-1156, 2016.

[13] M. J. Kwon, "A study on application of pattern design using principles of repetition," M.A. thesis, Dept. Architectural Engineering, Kookmin University. 